"Golf courses copy recently deglaciated topography in Scotland"; "Natural gas is to oil as politicians are to statesmen" McPhee got to the heart of what four geologists thought in the early days of plate tectonics. The subplot to all the earliest books, and in particular Basin and Range, was the arrival of plate theory. The second book, In Suspect Terrain, is inadvertently the most revealing about this. The book's guide is Anita Harris, a field geologist with the US Geological Survey, who argues: "I get all heated up when some sweet young thing with three geology courses tells me about global tectonics, never having gone on a field trip to look at a rock"; "with the plate-tectonic model anybody can write a history of an area without having been there".

The books succeed or fail on the back of their main personality, which is why In Suspect Terrain is the weakest of the original four (as one tires of the bias) and Assembling California is perhaps the best, in the company of the erudite and charming Eldridge Moores, founder of the journal Geology, who was born in a tiny mining town in Arizona.

As the series continued, McPhee began to lose something of the innocence that inspired Basin and Range, and with it some of his ear for the unfamiliar. No longer will he be reading the road-cutting graffiti as his companion studies the rocks. Increasingly, he comes to sound like a geologist, quoting arcane terminology, lists of world localities where ophiolites of a particular class can be viewed, and even sets of papers and authors.

The shift is also evident in the production of this collection. The additional chapter on the Craton is intended to "complete" the geology of North America. The project now has ambitions to be a more comprehensive textbook, and is accompanied by an introduction that provides signposts on where in the text to find the key elements of geology. The original books were notable for their absence of illustration, perhaps the first books on geology for 150 years to have chosen to allow the words alone to paint the scene. The inclusion here of some simple, but almost entirely uninformative, relief maps breaks this convention.

These ambitions are mistaken. The novelty and freshness of the original project was precisely because it wandered, serially, anecdotally, across America and geology, dipping in and out of subjects, of processes, theories and ages of geological time, as each new stone was overturned to set off some new story or reflection. As a commentator $\mathrm{McPhee}$ is excellent, but he lacks the scientific perspective to gauge a debate accurately or to check sources. He describes, for example, Scotland as laden with two miles of ice in the last Ice Age - a threefold exaggeration. It is also a pity that the one personality missing from the story is McPhee himself, for which, to find out about some of the other anthro- pological aspects of geology — the long time spent away from home, and the accompanying disruption to family life - it is worth reading his daughter Martha's fictional Bright Angel Time.

Yet McPhee's original project, as articulated in the first book, was actually quite profound, and his books remain very readable. Earth scientists have a debt to McPhee for his coining of the term "Deep Time", a modern restatement of James Hutton's "no vestige of a beginning, no prospect of an end", to describe the impossibility of confronting the unfathomable depths of prehistory, the inconceivable currency of millions and billions of years that becomes so glibly familiar to geologists once they have passed through the first introductorylectures.

Robert Muir-Wood, managing editor of Terra Nova and author of The Dark Side of the Earth (Unwin Hyman, 1985), is at Risk Management Solutions Ltd, Peninsular House, 30-36 Monument Street, London EC3R 8LJ, UK

\section{Monk-y puzzles}

\section{The Mathematical Tourist}

by Ivars Peterson

W. H. Freeman: 1998. 256pp. \$14.95 (pbk)

\section{Tracking the Automatic Ant}

by David Gale

Springer: 1998. 241pp. \$30, £22.50

\section{Andrew Bremner}

The ant is a fascinating object of study, and anyone who has hefted the compendious, weighty (and Pulitzer prize winning) tome The Ants by Bert Hölldobler and Edward O. Wilson, surely has tremendous regard for these creatures. Mathematicians, too, have now taken the ant to their hearts, and it provides one of the common links between the two books under review, which are compilations of material that has previously appeared in Science News and The Mathematical Intelligencer respectively. The former book is an updated version of Peterson's very successful first edition, published almost 10 years ago; the second collects the "Mathematical Entertainment" columns that appeared in the Intelligencer between 1991 and 1996, while Gale was editor.

The books differ in their emphasis. Peterson sets out to explain to the general reader (one assumes that the general reader of Science News has a modest mathematical background) some of the startling discoveries and recent advances that have caused excitement in mathematics. This is a difficult task, because it requires the author to have the ability not only to grasp thoroughly the mathematical concepts involved, but also to translate these concepts into entertaining prose for the non-specialist reader.

Mathematicians are really monks, but rare indeed is the illuminating manuscript. It is thus a pleasure to find a journalist like Peterson who can write so lucidly, on rare occasions perhaps a trifle earnestly, about knots and DNA, about crystallography and Penrose tilings, about discoveries shedding light on the relationship between fourdimensional geometry and the physical theories of the nature of time, and about cryptography and prime factorization.

Occasionally, the author breathlessly takes on Baedeker: "beauty spots", "unnamed wonders", and "innumerable strange sights to view" can be found if the tourist in the Mandelbrot Set explores the area with real part between 0.26 and 0.27 and imaginary part between 0 and $0.01 \mathrm{i}$ ("or why not try -0.76 to -0.74 and 0.01 i to $0.03 i$ ?"). The Mathematical Tourist conveys vividly the excitement, the usefulness, and the sheer beauty of the subject.

Gale, in contrast, writes for the pleasureseeking mathematician, professional and amateur. These columns have a similar form to those of Martin Gardner and Ian Stewart in Scientific American, with an emphasis on recreational mathematics, though as we know, this is often underpinned by eminently serious stuff. Extracting tidbits for mention here is difficult to do fairly; the book contains as much to savour on each page as a compendium of short stories by Saki.

Try for instance the following problem. Each of two boxes contains an integer printed on a card; the two integers are known to be distinct. You open one of the boxes at random, and then have to guess whether the other contains a larger or a smaller integer. Is there anything you can do to give yourself a better than even chance of guessing correctly? The surprising answer is yes. Or what about the (simple) theorem that a sufficiently high power of two will have leading digits that encode the works of Shakespeare? "To be ..." for example appears at the start of $2^{9965483}=20150205 \ldots$. A five-line algorithm is provided for computing the first such power to yield a chosen sequence, which raises interesting possibilities: perhaps a unique personalized present for that in-law who has everything (provided of course your PC can cope).

What becomes apparent from reading these books is the role now played by computers in mathematics, suggesting a shift in nature of the subject from deductive science to empirical science. For the technophobe this may appear discouraging, perhaps even alarming, with the discovery that machines have now been used to prove theorems. But the ability to amass vast amounts of experimental data certainly has enormous ramifications; without it much of the territory explored in these books would remain uncharted.

Andrew Bremner is in the Department of

Mathematics, Arizona State University, Tempe, AZ 85287-1804, USA. 